\title{
PEMANFAATAN PATI UMBI TALAS (Colocasia esculenta L.) SEBAGAI BAHAN PEMBUATAN BIOPLASTIK
}

\author{
Maria Stefania Naki, Ignatius Antonius M S Wake
}

SMAS Katolik Regina Pacis Bajawa, Flores-NTT, Indonesia

Email: nakifaniia@gmail.com, dewawake@gmail.com

\section{Diterima \\ 22 Juni 2020 \\ Direvisi \\ 6 Juli 2020 \\ Disetujui \\ 10 Juli 2020}

INFO ARTIKEL

\section{Kata Kunci:}

bioplastics, citric acid, clay, chitosan, glycerol

\section{ABSTRAK}

Bioplastik menjadi salah satu alternatif pengunaan plastik yang ramah lingkungan karena mudah terurai. Pada penelitian ini digunakan pati umbi talas (Colocasia esculenta L.) dengan campuran asam sitrat, plasticizer gliserol, sedangkan Fillernya clay dan chitosan. Tujuan penelitian ini adalah mengetahui bentuk fisik bioplastik, kuat tarik (tensile strength) dan pemanjangan (elongasi) bioplastik sesuai kualitas SNI serta kemampuan bioplastik ini dapat terurai (biodegradable) dalam waktu yang relatif singkat. Penelitian ini berlangsung dari tanggal 26 Juli-30 September 2021 di laboratorium FKIP KIMIA Universitas Nusa Cendana Kupang dan Laboratorium Biologi SMAS Katolik Regina Pacis Bajawa. Metode penelitian yang digunakan Melt Intercalation dengan sedikit inovasi penambahan asam sitrat dengan variasi pada filler clay dan chitosan yaitu 0,2gr, 0,4gr, 0,8gr, dan 1,0gr. Metode pengolahan data secara kualitatif dan kuantitatif berdasarkan hasil penelitian. Data yang diperoleh kemudian dianalisis bentuk fisik dan kemampuan biodegradable, kemudian dilakukan uji kuat tarik dan persen pemanjangan menggunakan persamaan fisika. Hasil penelitian pada filler clay 0,4gr yang menunjukkan bentuk fisik permukaan halus dan tidak retak. Hasil uji tarik yang terbaik diperoleh pada sampel clay $0,4 \mathrm{gr}$, dengan kekuatan tarik $4 \mathrm{~N}=37,5 \mathrm{MPa}$. Hasil uji tarik ini sesuai SNI dimana nilai kuat tarik berkisar 24,7$302 \mathrm{MPa}$. Persen pemanjangan pada semua variasi filler clay maupun chitosan memenuhi kriteria SNI dimana nilai persen pemanjangan berkisar $21-220 \%$ dan tertinggi persen elongasi terdapat pada chitosan 0,4gr dengan nilai pemanjangan adalah $150 \%$. Hasil uji penguraian bioplastik melalui metode perendaman sampel dalam aquades selama 48 jam, diperoleh hasil adanya penurunan berat bioplastik akibat aktivitas mikroorganisme.

\section{ABSTRACT}

Bioplastics become one of the alternatives to the use of plastics that are environmentally friendly because they are easy to decompose. In this study used taro tuber starch (Colocasia esculenta L.) with a mixture of citric acid, glycerol plasticizer, while filler clay and chitosan. The purpose of this study is to find out the physical form of bioplastics, tensile strength and bioplastic elongation according to the quality of SNI and the ability of biodegradable biodegradable in a relatively short time. The study took place from July 26 to September 30, 2021 at the FKIP KIMIA laboratory of Nusa Cendana Kupang University and the Biology Laboratory of Regina Pacis Bajawa Catholic High School. The research method used by Melt Intercalation with a little innovation in the addition 


of citric acid with variations in clay and chitosan fillers is 0.2gr, 0.4gr,
O.8gr, and 1.0gr. Qualitative and quantitative data processing methods
based on research results. The data obtained then analyzed physical form
and biodegradable capabilities, then conducted strong tensile and percent
lengthening tests using physical equations. The results of the study on
O.4gr clay fillers showed a smooth and non-cracking surface physical
shape. The best tensile test results were obtained on a clay sample of
O.4gr, with a tensile strength of $4 N=37.5 M P a$. The results of this tensile
test are in accordance with the SNI where the strong value of the
attraction ranges from 24.7-302MPa. The percentage of lengthening in
all variations of clay fillers and chitosan meets the SNI criteria where the
value of lengthening percentage ranges from $21-220 \%$ and the highest
percentage elongation is found in chitosan 0.4gr with the elongation
value is $150 \%$. The results of the bioplastic decomposition test through
Keywords:
bioplastics, citric sample immersion method in aquades for 48 hours, obtained the
clay,
acid,
chitosalts of a decrease in bioplastic weight due to the activity of
microorganisms.

\section{Pendahuluan}

Kementerian Lingkungan Hidup dan Kehutanan (KLHK) pada tahun 2020, merilis data bahwa di Indonesia dihasilkan sekitar 67,8 juta ton sampah plastik yang tertimbun dalam tanah (KLHK, 2020) Angka yang sangat tinggi dalam menghasilkan sampah plastik setiap tahunnya, pada hal membutuhkan waktu 500 sampai 1000 tahun untuk dapat terurai (Manuela Kasper-Claridge, 2018). Lamanya waktu penguraian sampah plastik ini, akan membawa masalah lain terhadap lingkungan hidup (Saleh \& Utami, 2021). Penggunaan plastik secara terus menerus dapat pula menimbulkan masalah krisisnya minyak bumi dan gas bumi yang dipakai sebagai bahan dasar pembuatan plastik konvensional (Maryuni et al., 2018)

Pembuatan plastik menggunakan bahan dasar dari minyak dan gas alam secara terus menerus maka akan diperkirakan habis sekitar sembilan tahun ke depan, jika tidak ada bahan alternatif penghasil plastik. Solusi yang baik dan tepat untuk mengurangi penggunaan minyak dan gas bumi tersebut yakni menggunakan bahan organik sebagai bahan alternatif pembuatan plastic (Swani, J. N., \& Singh, 2010). Bahan alternatif pengganti minyak dan gas bumi dalam pembuatan plastik antara lain bahan organik yang memiliki kandungan pati (Ramadhan \& Nugraha, 2021).

Pati merupakan bahan alternatif dalam pembuatan bioplastik, karena ada biopolimer dalam kandungan pati (Saputra \& Lutfi, 2015). Bahan-bahan organik yang menghasilkan pati antara lain jagung, sagu, umbi kayu, umbi jalar, dan umbi talas (Wahidah, 2017). Pati Umbi talas juga mengandung komponen amilosa dan amilopektin yang mempunyai rantai lurus dan larut dalam air serta memberi sifat keras (Tutik Sri Wahyuni, 2010). Campuran pati dengan beberapa bahan plasticizer organik dan filler mampu membentuk kualitas plastik biodegradable sesuai standar SNI.

Tanaman umbi talas tumbuh subur di Indonesia yang beriklim tropis, termasuk di daerah Bajawa, Kabupaten Ngada, Flores, Nusa Tenggara Timur. Tanaman umbi talas ini digunakan sebagian besar masyarakat Ngada sebagai bahan makanan untuk ternak, pada hal umbi talas ini memiliki kandungan pati yang juga dapat dimanfaatkan sebagai bahan alternatif pembuatan plastik (Tutik Sri Wahyuni, 2010). Kandungan pati yang ada pada umbi talas bisa menjadi alternatif pengganti plastik konvensional karena sangat biodegradable (Kamsiati et al., 2017). 
Persoalan penggunaan plastik konvensional harus terselesaikan, maka melalui penelitian bioplastik dengan bahan dasar pati umbi talas penting dilakukan. Penelitian bioplastik belum pernah dilakukan di Kabupaten Ngada dengan menggunakan bahan dasar pati dengan campuran beberapa bahan plasticizer dan filler. Oleh karena itu perlu dilakukan penelitian bioplastik dari pati umbi talas sebagai salah satu solusi mengatasi pencemaran lingkungan akibat plastik konvensional serta permasalahan menipisnya minyak bumi dan gas bumi.

SMAS Katolik Regina Pacis Bajawa. Penelitian bioplastik pati umbi talas ini menggunakan metode Melt Intercalation (Melani et al., 2018). Melt Intercalation dengan sedikit modifikasi penambahan asam sitrat serta adanya variasi konsentrasi pada filler clay dan chitosan yaitu $0,2 \mathrm{gr}, 0,4 \mathrm{gr}$, $0,8 \mathrm{gr}$, dan 1,0gr.

Metode pengolahan data secara kualitatif dan kuantitatif berdasarkan hasil penelitian. Data yang diperoleh kemudian dianalisis bentuk fisik dan kemampuan biodegradable, kemudian dilakukan uji kuat tarik (persamaan 1) dan uji persen pemanjangan (persamaan 2). Persamaan 1 dan persamaan 2 dapat dilihat pada tabel berikut :

\section{Metode Penelitian}

Penelitian ini dilaksanakan pada tanggal 26 Juli-30 September 2021 bertempat di laboratorium FKIP KIMIA Universitas Nusa Cendana Kupang dan Laboratorium Biologi SMAS Katolik Regina Pacis Bajawa. Penelitian bioplastik pati umbi talas ini menggunakan metode Melt Intercalation (Melani et al., 2018). Melt Intercalation dengan sedikit modifikasi penambahan asam sitrat serta adanya variasi konsentrasi pada filler clay dan chitosan yaitu $0,2 \mathrm{gr}, 0,4 \mathrm{gr}$, $0,8 \mathrm{gr}$, dan $1,0 \mathrm{gr}$.

Metode pengolahan data secara kualitatif dan kuantitatif berdasarkan hasil penelitian. Data yang diperoleh kemudian dianalisis bentuk fisik dan kemampuan biodegradable, kemudian dilakukan uji kuat tarik (persamaan 1) dan uji persen pemanjangan (persamaan 2). Persamaan 1 dan persamaan 2 dapat dilihat pada tabel berikut :

Tabel 1

Uji Kuat Tarik ( persamaan 1)

\begin{tabular}{llrl}
\hline & \multicolumn{2}{c}{ Rumus } & \multicolumn{1}{c}{ Keterangan } \\
\hline Persamaan 1 & $\sigma=$ & F maks & $\sigma=$ kekuatan tarik $(\mathrm{N} / \mathrm{m} 2)$ \\
& & F maks = beban maksimum $(\mathrm{kg})$ \\
AO &
\end{tabular}

Tabel 2

Uji Persen Pemanjangan (persamaan 2)

\begin{tabular}{rccc}
\hline & A0 & $=$ luas penampang awal $\left(\mathrm{m}^{2}\right)$ \\
\hline Persamaan 2 & $\varepsilon$ & $=$ regangan $(\%)$ \\
\hline$\varepsilon={ }^{\Delta 1} \times 100 \%$ & $\Delta \mathrm{l}$ & $=$ penambahan panjang $(\mathrm{cm})$ \\
\hline & $1_{0}$ & $=$ panjang mula-mula $(\mathrm{cm})$ \\
\hline
\end{tabular}




\section{Hasil dan Pembahasan}

A. Hasil Penelitian

1 Bentuk Fisik Bioplastik

Hasil penelitian bioplastik ditampilkan dalam tabel berikut ini

Tabel 3

Karakteristik bioplastik campuran pati, asam sitrat, gliserol dengan variasi filler clay

\begin{tabular}{ccccc}
\hline No & $\begin{array}{c}\text { Variasi } \\
\text { Filler } \\
\text { Clay }\end{array}$ & Warna & Tekstur & Keterangan \\
\hline 1 & $0,2 \mathrm{gr}$ & $\begin{array}{c}\text { Coklat } \\
\text { sedikit } \\
\text { keruh }\end{array}$ & $\begin{array}{c}\text { Permukaan } \\
\text { kasar }\end{array}$ & Retak \\
& & Coklat & $\begin{array}{c}\text { Permukaan } \\
\text { halus }\end{array}$ & Tidak retak \\
\hline 2 & $0,4 \mathrm{gr}$ & $\begin{array}{c}\text { Cerang } \\
\text { terlat }\end{array}$ & $\begin{array}{c}\text { Permukaan } \\
\text { kasar }\end{array}$ & Retak \\
\hline 3 & $0,6 \mathrm{gr}$ & $\begin{array}{c}\text { Coklak } \\
\text { terang }\end{array}$ & \\
\hline 4 & $0,8 \mathrm{gr}$ & $\begin{array}{c}\text { Coklat } \\
\text { terang }\end{array}$ & $\begin{array}{c}\text { Permukaan } \\
\text { kasar }\end{array}$ & Retak \\
\hline 5 & $1,0 \mathrm{gr}$ & Coklat & Permukaan & Retak \\
\hline
\end{tabular}

2 Kuat Tarik Bioplastik (Tensile Strength)

Data kuat tarik pada penelitian ini dapat dilihat pada gambar berikut ini :
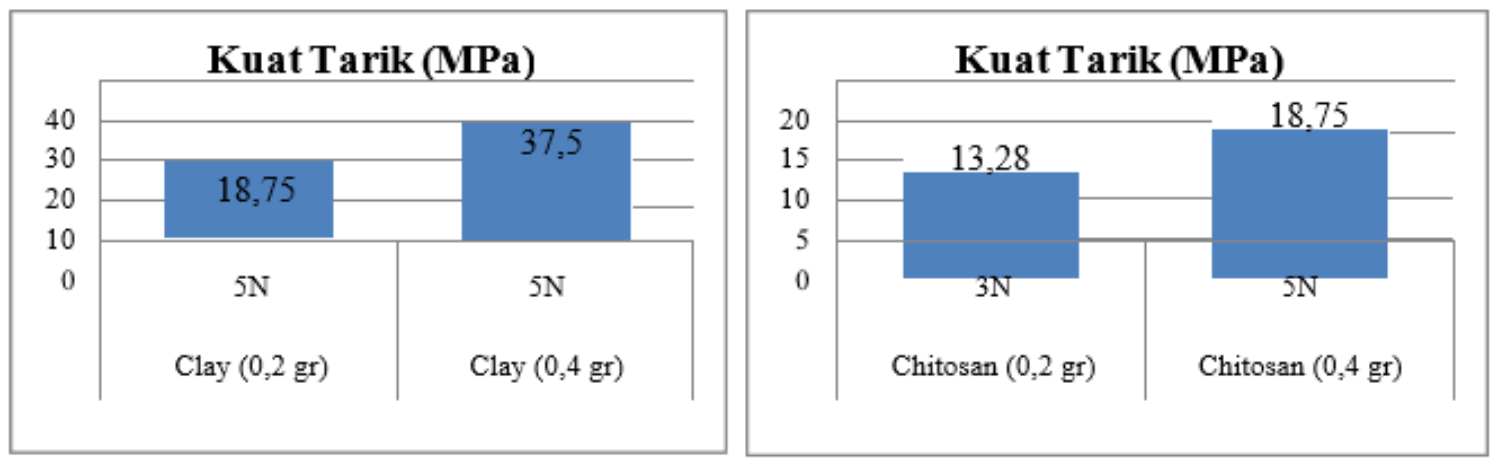

Gambar 1

Data Kuat Tarik Bioplastik (Tensile strenght)

3 Persen pemanjangan (Elongasi)

Data persen pemanjangan pada penelitian dapat dilihat pada gambar berikut ini :
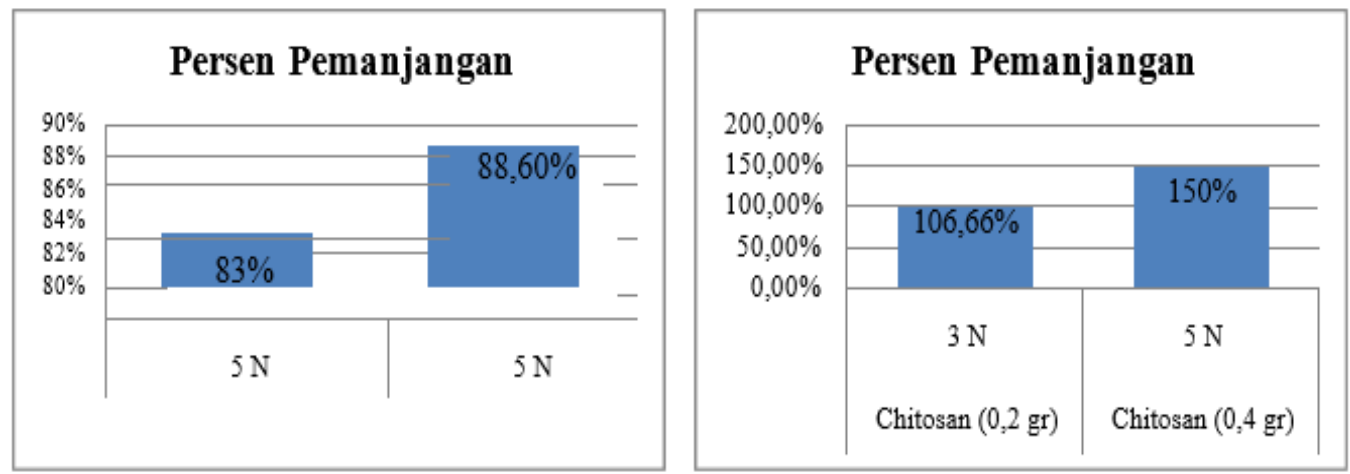

Gambar 2 Data Persen Pemanjangan Bioplastik (Elongasi) 
4 Penguraian Bioplastik (Biodegrad ble)

Proses penguraian bioplastik menggunakan empat sampel penelitian sebagai perwakilan. Pada proses ini dilakukan secara sederhana dengan metode perendaman sampel pada aquadest sebanyak $100 \mathrm{ml}$ dan direndam selama 48 jam. Data yang di ukur adalah berat mulu-mula (W0) sebelum direndam sampai berat akhir (W3) setelah direndam selama 48 jam. Hasil pengamatan ditunjukkan pada gambar berikut

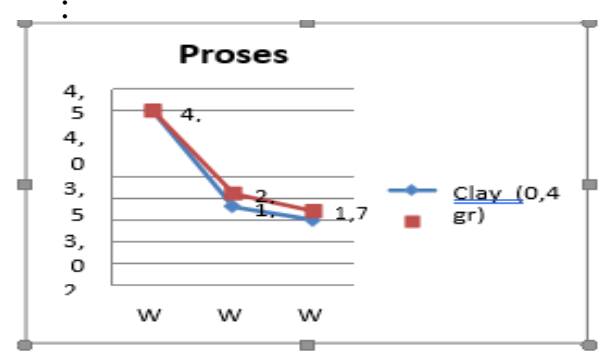

Gambar 3 Data Penguraian Bioplastik (Biodegradable

\section{B. Pembahasan}

1. Bentuk Fisik Bioplastik

Bentuk fisik bioplastik terbaik yang dihasilkan pada campuran pati dengan filler clay 0,4 gr dengan ciri-ciri warna coklat terang, tekstur halus dan tidak retak. Selain itu, karakteristik bioplastik yang terbaik juga diperoleh dari campuran pati, chitosan, dan gliserol 0,6gr dengan ciri- ciri warna putih, permukaan kasar, dan tidak retak. Variasi filler dengan besaran kurang dari 0,4 gr atau lebih dari 0,4 gr akan membentuk bioplastik dengan tekstur permukaan yang kasar serta akan membuat bioplastik menjadi retak.

Tampilan fisik pada bioplastik yang berwarna coklat terang dihasilkan dari clay yang merupakan tanah liat sedangkan berwarna putih karena adanya chitosan yang merupakan sisa cangkang kerang yang di daur ulang. Campuran asam sitrat, filler clay dan chitosan, serta plasticizer gliserol merupakan kombinasi senyawasenyawa organik yang mampu berikatan membentuk gugus polimer pendek sehingga dapat mengisi pori-pori bioplastik dan terbentuk bioplastik yang sesuai standarisasi SNI. Adanya plasticizer mampu mengikat pati dari umbi talas agar menjadi elastis, sedangkan tambahan filler sebagai penguat atau perekat dan asam sitrat menjadikan bioplastik memiliki kuat tarik yang baik.

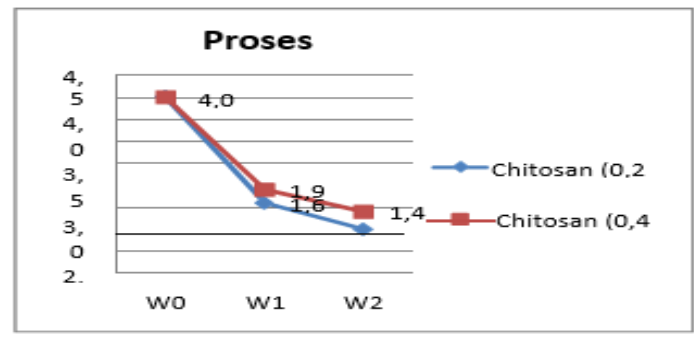

Kuat Tarik Bioplastik (Tensile Strength)

Uji kuat tarik bioplastik yang dilakukan pada penelitian ini menggunakan 4 sampel yang memiliki tampilan fisik bioplastik baik yaitu campuran clay $0,2 \mathrm{gr}$ dan $0,4 \mathrm{gr}$, chitosan 0,2gr, dan chitosan 0,4gr, dengan menggunakan gaya tarik sebesar $1 \mathrm{~N}$ hingga $5 \mathrm{~N}$. Uji tarik bioplastik dengan capuran caly 0,2 gr diperoleh nilai kuat tarik sebesar $18,5 \mathrm{MPa}$ dengan kekuatan tarik sebesar $5 \mathrm{~N}$ dan nilai kuat tarik tersebut belum sesuai kriteria SNI. Pada uji tarik bioplastik dengan campuran clay $0,4 \mathrm{gr}$ diperoleh nilai kuat tarik sebesar $37,5 \mathrm{MPa}$ dan sesuai dengan SNI dimana nilai kuat tarik berkisar 24,7-302MPa. Hasil uji tarik yang terbaik diperoleh pada campuran clay 0,4 gr dengan nilai kuat tarik adalah $37,5 \mathrm{MPa}$ dengan kekuatan tarik $5 \mathrm{~N}$. Hal ini menunjukan bahwa peningkatan nilai kuat tarik diakibatkan pada penambahan variasi filler clay. Penambahan variasi filler clay dapat meningkatkan nilai kuat tarik ini disebabkan oleh peningkatan interaksi gaya tarik menarik antar molekul dalam bioplastik.

3. Persen pemanjangan (Elongasi)

Uji pemanjangan bioplastik yang dilakukan pada penelitian ini 
menggunakan sampel clay 0,2gr dan $0,4 \mathrm{gr}$, serta chitosan $0,2 \mathrm{gr}$ dan $0,4 \mathrm{gr}$. Gaya yang diberikan untuk mendapakan persen elongan berkisar antar $1 \mathrm{~N}-5 \mathrm{~N}$. Diperoleh hasil persen elongasi pada setiap sampel adalah memenuhi kriteria SNI yaitu 21-220\%. Hasil uji pemanjangan terbaik diperoleh pada sampel chitosan $0,4 \mathrm{gr}$ dengan nilai pemanjangan adalah $150 \%$.

Menurut penelitian yang telah dilakukan oleh Sanjaya dan Puspita, (2011), semakin banyak chitosan yang digunakan maka sifat mekanik dan ketahanan terhadap air dari produk bioplastik yang dihasilkan semakin baik, hasil optimum dimana hasil optimum. diperoleh pada komposisi kitosan $2 \%$, namun pada penelitian ini hasil persen pemanjangan optimum pada chitosan 0,4gr. Hal ini membuktikan bahwa pati umbi talas dengan campuran filler chitosan dan gliserol merupakan kombinasi yang tepat untuk membentuk bioplastik dengan persen pemanjangan yang memenuhi standarisasi menurut SNI.

4. Penguraian Bioplastik (Biodegradable) Uji penguraian bioplastik yang dilakukan pada penelitian ini menggunakan sampel clay $0,4 \mathrm{gr}$ dan $0,6 \mathrm{gr}$ serta chitosan $0,2 \mathrm{gr}$ dan $0,4 \mathrm{gr}$ yang selanjutnya direndam dalam gelas beaker yang berisi aquades sebanyak $100 \mathrm{ml}$ selama 48 jam. Berat dari masing masing sampel bioplastik sebelum direndam adalah 4gr, setelah direndam selama 48 jam dan dilakukan pengukuran berat bioplastik mengalami penurunan. Secara morfologi bioplastik yang paling bagus adalah bioplastik dengan penambahan clay karena strukturnya berubah menjadi seperti jely, sementara chitosan ketika direndam didalam aquades selama 48jam menjadi sangat hancur. Dalam proses perendaman bioplastik dengan aquades diletakkan diruangan terbuka sehingga menyebabkan mikroba dan bakteri dapat membantu proses degradasi bioplastic.

\section{Kesimpulan}

Hasil penelitian pada filler clay $0,4 \mathrm{gr}$ yang menunjukkan bentuk fisik permukaan halus dan tidak retak. Hasil uji tarik yang terbaik diperoleh pada sampel clay 0,4gr, dengan kekuatan tarik $4 \mathrm{~N}=37,5 \mathrm{MPa}$. Hasil uji tarik ini sesuai SNI dimana nilai kuat tarik berkisar 24,7-302MPa. Persen pemanjangan pada semua variasi filler clay maupun chitosan memenuhi kriteria SNI dimana nilai persen pemanjangan berkisar $21-220 \%$ dan tertinggi persen elongasi terdapat pada chitosan 0,4gr dengan nilai pemanjangan adalah $150 \%$. Hasil uji penguraian bioplastik melalui metode perendaman sampel dalam aquades selama 48 jam, diperoleh hasil adanya penurunan berat bioplastik akibat aktivitas mikroorganisme.

\section{Bibliografi}

Kamsiati, E., Herawati, H., \& Purwani, E. Y. (2017). Potensi pengembangan plastik biodegradable berbasis pati sagu dan ubikayu di Indonesia. Jurnal Penelitian Dan Pengembangan Pertanian, 36(2), 67-76.Google Scholar

\section{KLHK. (2020). Indonesia Memasuki Era Baru Pengelolaan Sampah. https://www.menlhk.go.id/site/single_po st $/ 2753$}

Manuela Kasper-Claridge. (2018). Bagaimana Singkong Bantu Perangi Sampah Plastik di Indonesia.

https://www.dw.com/id/bagaimanasingkong-bantu-perangi-sampah-plastikdi-indonesia/a-46209280

Maryuni, A. E., Mangiwa, S., \& Dewi, W. K. (2018). Karakterisasi Bioplastik Dari Karaginan Dari Rumput Laut Merah Asal Kabupaten Biak Yang Dibuat Dengan Metode Blending Menggunakan Pemlastis Sorbitol. Jurnal Kimia Avogadro, 2(1), 1-9. Google Scholar

Melani, A., Herawati, N., \& Kurniawan, A. F. (2018). Bioplastik Pati Umbi Talas Melalui Proses Melt Inter Google Scholar calation. Jurnal Distilasi, 2(2), 
Pemanfaatan Pati Umbi Talas (Colocasia Esculenta L.) Sebagai Bahan Pembuatan Bioplastik

53-67. Google Scholar

Ramadhan, M. O., \& Nugraha, J. F. (2021). Potensi Pati Dari Limbah Biji Buah Sebagai Bahan Bioplastik. Edufortech, 6(1). Google Scholar

Saleh, E. R. M., \& Utami, S. (2021). Karakteristik Fisik

Dan

Biodegradabilitas Bioplastik Dari Pati Kulit Pisang Mulu Bebe Dengan Penambahan Gliserol Yang Berbeda. Prosiding Seminar Nasional Lingkungan Lahan Basah, 6(2). Google Scholar

Saputra, A., \& Lutfi, M. (2015). Studi pembuatan dan karakteristik sifat mekanik plastik biodegradable berbahan dasar ubi suweg (amorphophallus campanulatus). Jurnal Keteknikan Pertanian Tropis Dan Biosistem, 3(1),

\section{1-6. Google Scholar}

Swani, J. N., \& Singh, B. (2010). Bioplastic and Global Sustainability. Plastic Reseach Online. Google Scholar

Tutik Sri Wahyuni. (2010). Pembuatan Dekstrin Dari Pati Umbi Talas Dengan Hidrolisis Secara Enzimatis. Universitas Pembangunan Nasional" Veteran " Jawa Timur Surabaya. http://eprints.upnjatim.ac.id/1947/1/file1. pdf Google Scholar

Wahidah, N. (2017). Kinetika Kimia Glukosa dari Pati Umbi Talas (Colocasia esculenta L. Schott) menggunakan Katalisator Enzim $\alpha$-amilase dan Glukoamilase. Universitas Islam Negeri Alauddin Makassar. Google Scholar

\section{Copyright holder :}

Maria Stefania Naki, Ignatius Antonius M S Wake (2020).

First publication right :

Action Research Literate

This article is licensed under: 